\title{
STRATEGI PENGELOLAAN HUTAN TANAMAN INDUSTRI UNTUK MITIGASI PERUBAHAN IKLIM MELALUI SKEMA REDD+
}

\author{
(The Strategies Of Industrial Forest Management To Mitigate Climate Change Through Redd+ \\ Schemes)
}

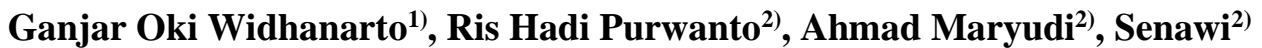 \\ ${ }^{1}$ Program Doktoral (S3), Program Studi Ilmu Kehutanan, Universitas Gadjah Mada,Yogyakarta, \\ Indonesia, ${ }^{2}$ Jurusan Manajemen Hutan, Fakultas Kehutanan, Universitas Gadjah Mada, Yogyakarta, \\ Indonesia \\ e-mail: ganjar_for@yahoo.com
}

\begin{abstract}
In 2009 the Goverment of Indonesia through the National Development Planning Agency has launched a Sectoral Climate Road Map, where the forestry sector relies on the development of industrial forest plantations (HTI) and forest management units (KPH) with the most efficient consideration of the cost budget and the effectiveness of technical feasibility for sustainability. The policy of HTI development by the Indonesian government furthermore has the opportunity to contribute to climate change mitigation through the REDD + scheme. This study aims to develop the strategies of industrial forest plantation management for REDD + schemes. This study analyzed internal factors that become strengths and weaknesses as well as external factors that become opportunities and threats using SWOT analysis to develop the strategies. The management of HTI in case of industrial forest plantation company PT. Finnantara Intiga (FI) was defined as an internal environment, while the external environment covers the entire environment related to HTI and REDD+. The results of the research showed that, the strength score is 1,817 and weakness is 1,186, so the difference is 0,631 (positive), as well as the element of opportunity is greater than the threat. The positive difference values both strength and opportunity indicate the priority strategies that will be used by PT. Finnantara Intiga in the $R E D D+$ scheme is an aggressive strategy (SO strategy)by using all the strengths and utilizing the opportunities.
\end{abstract}

Keywords : Industrial forest plantation, REDD+, SWOT Analysis,

\section{PENDAHULUAN}

Perubahan iklim telah menempatkan hutan menjadi obyek penting dalam mitigasi perubahan iklim global, hal ini meletakkan kembali kehutanan dalam agenda politik dunia. Hutan mempunyai peran dalam menahan laju emisi gas rumah kaca (GRK) dunia untuk mengatasi perubahan iklim global, mengingat emisi GRK terbesar salah satunya disebabkan penggundulan dan kebakaran hutan. Begitu juga dengan hutan di Indonesia, emisi GRK Indonesia diperkirakan sebesar 1,8 $\mathrm{GtCO}_{2} \mathrm{e}$ di tahun 2005, dimana sumber emisi paling besar $(63 \%)$ berasal dari kegiatan alih guna lahan serta kebakaran hutan dan lahan gambut, sedangkan konsumsi bahan bakar minyak menyumbangkan emisi GRK sebesar 19\% dari total emisi. Data tahun 2012 menyebutkan emisi GRK Indonesia turun menjadi $1,453 \mathrm{GtCO}_{2} \mathrm{e}$. Sektor utama yang berkontribusi mengeluarkan emisi adalah Sektor 
Penggunaan Lahan, Alih Fungsi Lahan, dan Kehutanan (Land Use, Land Use Change, and Forestry (LULUCF) termasuk kebakaran gambut $(47,8 \%)$ dan sektor energi $(34,9 \%)$ (MoEF, 2015).

Berbagai skema dan program terkait kehutanan dirancang di tingkat internasional maupun nasional dalam upaya mitigasi dan adaptasi perubahan iklim. Salah satu skema yang sedang dikembangkan saat ini adalah REDD (Reducing Emission from Deforestration and Forest Degradation), yaitu sebuah mekanisme dan program pengurangan emisi karbon yang bersumber dari pencegahan deforestasi dan degradasi hutan (REDD), serta kontribusi kegiatankegiatan konservasi, pengelolaan hutan lestari dan peningkatan stok karbon (REDD+). Jadi RED saja berarti mengurangi emisi dari deforestasi, REDD berarti mengurangi emisi seperti dalam lawas RED dan degradasi hutan, sedangkan REDD+, disamping mengurangi emisi seperti dalam lawas REDD, mengakui peran konservasi hutan, pengelolaan hutan lestari (PHL) dan peningkatan stok karbon (Angelson et al., 2010). Skema REDD+ tidak hanya akan mengurangi emisi dari deforestasi dan degradasi namun juga memberi imbalan jika mampu menurunkan emisi atau meningkatkan serapan $\mathrm{CO}_{2}$ di atmosfer. Dalam REDD+, satu ton $\mathrm{CO}_{2}$ yang disimpan di dalam pohon disebut sebagai kredit karbon sehingga pemilik hutan dapat memperoleh kredit sejumlah $\mathrm{CO}_{2}$ yang tidak dilepaskan ke udara atau yang berhasil disekuestrasi dari atmosfer.

Hutan, termasuk juga hutan tanaman industri (HTI) mengabsorbsi gas karbondioksida $\left(\mathrm{CO}_{2}\right)$ (salah satu sumber utama GRK) selama proses fotosintesis dan menyimpannya sebagai materi organik dalam biomassa tanaman. Banyaknya biomassa hutan sangat tergantung pada hasil yang diperoleh selama proses fotosintesis. Banyaknya materi organik yang tersimpan dalam biomassa hutan per unit luas dan per unit waktu merupakan salah satu pokok dari kajian produktivitas hutan. Produktivitas hutan merupakan gambaran kemampuan hutan dalam mengurangi emisi gas $\mathrm{CO}_{2}$ di atmosfer melalui aktivitas fisiologisnya (Heriansyah, 2005). Jika pengelola hutan dapat mengelola hutan secara lestari, maka HTI tidak saja secara kontinu mampu memasok kayu bagi industri tetapi juga dapat memberikan jasa lingkungan berupa penyerapan $\mathrm{CO}_{2}$. Peta Jalan Perubahan Iklim Sektoral Indonesia (Indonesia Climate Change Sectoral Roadmap/ICCSR), menunjukkan bahwa sektor kehutanan membidik bidang-bidang berikut untuk mendukung tercapainya target penurunan emisi : (1) reboisasi/rehabilitasi; (2) penanaman untuk produksi (Hutan Tanaman Industri/HTI dan Hutan Tanaman Rakyat/HTR); dan (3) pengembangan Kesatuan Pengelolaan Hutan/KPH. Tiga (3) kegiatan utama ini dikembangkan dengan mempertimbangkan kelayakan teknis, anggaran, dan skenario mitigasi 
sektor kehutanan. Pemerintah selanjutnya memilih pengembangan hutan tanaman industri (HTI) dan kesatuan pengelolaan hutan $(\mathrm{KPH})$ dengan pertimbangan yang paling efisien dari segi anggaran-biaya dan keefektifan dari kelayakan teknis untuk keberlanjutan. (Bappenas, 2009). Kebijakan pengembangan HTI oleh pemerintah Indonesia berpeluang untuk berkontribusi dalam mitigasi perubahan iklim melalui skema REDD+.

Potensi stok karbon di HTI dan kemampuannya dalam menurunkan emisi $\mathrm{CO}_{2}$, memberikan peluang bagi HTI untuk berkontribusi dalam upaya mitigasi perubahan iklim melalui skema REDD+ melalui peningkatan cadangan karbon (carbon enhancement), pengurangan emisi dari deforestasi dan degradasi hutan, dan pengelolaan hutan lestari (sustainable forest management). Keterlibatan perusahaan HTI dalam skema REDD+ memiliki dua (2) keuntungan, yaitu perusahaan selain memperoleh nilai finansial dari kayu yang diproduksinya juga dapat memperoleh insentif dana dari jasa lingkungan yang dihasilkannya berupa sequestrasi $\mathrm{CO}_{2}$, Hal ini sesuai dengan Permenhut No, 36/Menhut II/2009 tentang jasa lingkungan dari hutan produksi, dimana hutan produksi dapat berpartisipasi menurunkan karbon dalam upaya mitigasi perubahan iklim. Beberapa hal terkait dengan keterlibatan perusahaan HTI dalam skema REDD+ antara lain : seberapa besar kemampuan HTI dalam mensequestrasi $\mathrm{CO}_{2}$ yang dilihat dari dinamika stok karbon dalam ekosistem HTI, bagaimana komitmen perusahaan HTI dalam mewujudkan pengelolaan hutan yang lestari, apa saja ancaman dan resiko yang dapat menyebabkan pengelolaan HTI tidak lestari dan dapat menyebabkan menurunnya stok karbon dalam ekosistem HTI, dan bagaimana tata kelola hutan ditingkat pusat dan daerah yang mendukung pelaksanaan REDD+ dikaitkan dengan pengelolaan HTI. Penelitian ini bertujuan untuk menyusun strategi agar pengelolaan HTI dapat masuk dalam skema REDD+ dengan mengambil kasus di HTI PT. Finnantara Intiga Kalimantan Barat.

\section{METODE PENELITIAN}

Lokasi dan Waktu Penelitian

Penelitian ini dilakukan di hutan tanaman industri (HTI) PT. Finnantara Intiga (PT. FI), yang merupakan salah satu unit manajemen hutan tanaman yang ada di Indonesia yang mendapat Izin Usaha Pemanfaatan Hasil Hutan Kayu (IUPHHK) pada hutan tanaman berdasarkan Surat Keputusan Menteri Kehutanan RI Nomor 750/Kpts-II/1996 tanggal 2 Desember 1996 seluas \pm 299.700 Ha di Provinsi Kalimantan Barat. Secara geografis areal kerja PT. Finnantara Intiga terletak pada $0^{0} 00^{\prime} \mathrm{LU}$ - $0^{0} 50^{\prime}$ LU dan $110^{0} 30^{\prime}$ BT - $111^{0} 40^{\prime}$ BT. Secara administratif termasuk dalam 14 wilayah kecamatan di Kabupaten Sanggau, Sintang, dan Sekadau Provinsi Kalimantan Barat. Areal PT. Finnantara Intiga secara administrasi pemerintahan masuk dalam Kabupaten Sanggau seluas 105.412,55 Ha, Kabupaten Sekadau 53.662,90 Ha, dan Kabupaten Sintang 62.211,78 Ha. Berdasarkan fungsi kawasan hutan, 
yang masuk dalam kawasan hutan seluas 221.287,23 Ha dan areal penggunaan lain (APL) seluas 68.720,93 Ha (Anonim, 2007).

Hutan tanaman terdiri dari sekitar 95\% A. mangium. Kondisi areal kerja PT. Finnantara Intiga terletak pada ketinggian antara $11 \mathrm{~m} \mathrm{dpl} \mathrm{-} 300 \mathrm{~m} \mathrm{dpl}$ dengan topografi didominasi oleh kelas lereng datar yakni meliputi 78,58\% areal, kelas lereng landai $15,31 \%$, dan agak curam 6,11\%. Mengingat luasnya areal PT. FI, maka dalam pengelolaan areal kerja dibagi menjadi dua (2) area / wilayah : Sanggau dan Sintang. Area Sanggau dibagi ke dalam 4 distrik hutan : Mengkiyang, Entanjan, Jeropet, dan Beringin. Sedangkan area Sintang dibagi ke dalam 4 distrik hutan : Lubuk Tapa, Tumbang Ala, Mengaret, dan Tumbuk (Anonim, 2007)..

Berdasarkan data iklim yang diperoleh dari data klimatologi stasiun meteorologi Nanga Pinoh selama 10 tahun, termasuk dalam wilayah beriklim tropis dengan temperatur udara berkisar antara 26,32 ${ }^{\circ} \mathrm{C}-27,00{ }^{\circ} \mathrm{C}$ dengan kelembaban udara rata-rata bulanan antara 82,5 \% - 87,3 \%. Berdasarkan klasifikasi iklim Schmidt and Ferguson, areal IUPHHK-HTI PT Finnantara termasuk dalam kelas A (Sangat Basah) dengan kondisi hujan yang selalu turun sepanjang tahun.denganreratacurah hujan 2.962 mmtahun $^{-1}$ dan 217 hari hujan per tahun; bulan basah $(>100$ mm.bulan ${ }^{-1}$ ) terjadi sepanjang tahun. Kondisi iklim tersebut relatif menguntungkan untuk pertumbuhan hutan tanaman, terutama A. mangium. Areal PT. Finnantara Intiga seluruhnya berada dalam cakupan Daerah Aliran Sungai (DAS) Kapuas Tengah dan terbagi ke dalam 3 sub DAS yaitu Sub DAS Sekayam, Sub DAS SanggauMengkiang dan Sub DAS Belitang.Di dalam areal ini terdapat 11 Satuan Peta Lahan (SPL) dengan 3 SPL dominan yaitu Lawanguan (LWW), Teweh (TWH), dan Honja (HJA) yang meliputi 92,3\% areal kerja. Jenis tanah pada ketiga SPL tersebut adalah Podsolik Merah Kunin, Podsolik Kuning, dan Aluvial kelabu, dengan lereng 2-8\% dan 16-25\%. Kesesuaian lahan ketiga SPL untuk Acacia mangium tergolong S3 (sesuai marginal), dengan faktor pembatas tergolong sedang dan secara teknis dapat diatasi yaitu masalah erosi dan kapasitas tukar kation (KTK) rendah (Anonim, 2007). Pengambilan data dilakukan dari Juni hingga Desember 2017.

Pengumpulan Data

Penelitian ini akan menganalisis faktor internal yang menjadi kekuatan dan kelemahan serta faktor eksternal yang menjadi peluang dan ancaman, bagi HTI PT.Finnantara Intiga untuk bisa masuk dalam skema REDD+. Pembangunan dan pengelolaan HTI oleh PT. Finnantara Intiga (FI) ditetapkan sebagai lingkungan internal, sedangkan lingkungan eksternal mencakup keseluruhan lingkungan di luar aspek pembangunan dan pengelolaan HTI oleh PT. FI, tetapi masih terkait dengan HTI dan REDD+.

Faktor internal yang menjadi kekuatan dan kelemahan serta faktor eksternal yang menjadi peluang dan ancaman, kemudian dilakukan 
identifikasi dan evaluasi. Faktor internal yang diindentikasi dan di evaluasi meliputi tiga aspek, yaitu : (a) produksi (standing stock), (b) ekologi dan pengelolaan lingkungan hidup, (c) social, ekonomi, dan budaya; sedangkan faktor eksternal meliputi (a) kebijakan dan politik daerah, (b) kebijakan dan politik nasional (c) kebijakan dan politik internasional.

Data-data mengenai faktor internal dan eksternal didapat dari pengumpulan data-data primer terkait dalam pembangunan dan pengelolaan HTI dan REDD+, selain itu data juga dari hasil wawancara dengan berbagai pihak (seperti pemilik Perusahaan HTI, Pejabat Kementerian Lingkungan Hidup dan Kehutanan, Dinas Kehutanan Kabupaten dan Propinsi yang mengurusi kegitan HTI, Lembaga Penelitian, Perguruan Tinggi, dan Lembaga Swadaya Masyarakat (LSM)), dan data-data sekunder pendukung lainnya yang terkait dengan REDD+. Dari masing-masing instansi unit kerja di atas yang dijadikan sampel penelitian minimal 2 (dua) responden. Untuk mendapatkan informasi dari berbagai narasumber melalui analisis SWOT dapat digunakan metode survey terhadap pihak-pihak (stakeholders) dengan langkah-langkah sebagai berikut:

1. Penilaian faktor internal dan eksternal. Di sini responden memberikan preferensi opini terhadap faktor-faktor internal dan eksternal dari institusi pada saat ini dan perkiraan di masa mendatang.
2. Penilaian urgensi. Di sini responden diminta untuk menilai tingkat urgensi faktor tersebut untuk ditangani. Penilaian ini berhubungan dengan skala prioritas dalam menyelesaikan persoalan-persoalan pembangunan yang tercermin melalui faktor-faktor yang dinilai.

Penentuan sampel dilakukan secara purposive sampling, yaitu penentuan sampel dengan pertimbangan tertentu (Sugiyono, 2004), yaitu tidak semua orang/pihak mengetahui, memahami, terlibat dan terkena dampak dalam pembangunan dan pengelolaan HTI terkait REDD+.

\section{ANALISIS DATA}

Analisis data dalam penelitian ini menggunakan analisa SWOT (SWOT Analysis) Menurut Rangkuti, F. (2006), analisa SWOT adalah suatu metode perencanaan strategis yang digunakan untuk mengevaluasi faktor-faktor yang menjadi kekuatan (Strengths), Kelemahan (Weaknesses), Peluang (Opportunities), dan Ancaman (Threats) yang mungkin terjadi dalam mencapai suatu tujuan dari kegiatan proyek/kegiatan usaha atau institusi/lembaga dalam skala yang lebih luas. Faktor-faktor internal dan eksternal yang telah diidentifikasi, kemudian diberikan bobot ( weightening) dan peringkat (rating) untuk menentukan lima faktor yang paling dominan dalam masing-masing kolom kekuatan (Strengths), kelemahan (Weaknesses), peluang (Opportunities), dan ancaman (Threats).

Faktor- factor yang paling dominan kemudian dimasukan dalam Matriks 
SWOT yang akan menghasilkan 4 (empat) kemungkinan strategi alternatif, yaitu : Strategi (SO). Strategi ini dibuat berdasarkan jalan pikiran perusahaan, yaitu dengan memanfaatkan seluruh kekuatan untuk merebut dan memanfaatkan peluang sebesarbesarnya. Strategi (WO), strategi ini diterapkan berdasarkan pemanfaatan peluang yang ada dengan cara meminimalkan kelemahan yang ada. Strategi (ST), ini adalah strategi dalam menggunakan kekuatan yang dimiliki perusahaan untuk mengatasi ancaman. Strategi (WT), strategi ini didasarkan pada kegiatan yang bersifat defensive dan berusaha meminimalkan kelemahan yang ada serta menghindari ancaman. Unsur-unsur faktor internal dan eksternal diberi nilai bobot dan peringkat berdasarkan penilaian responden, kemudian dihitung skornya. Skor merupakan hasil perkalian dari nilai bobot dengan peringkat, jika unsur kekuatan skornya lebih besar dari unsur kelemahan maka menunjukkan unsur kekuatan lebih dominan dibanding kelemahannya, begitu juga untuk peluang dan ancaman serta hal ini berlaku sebaliknya.

Selanjutnya dilakukan analisis grand strategy dilakukan untuk menentukan strategi prioritas dari alternatif strategi yang telah dibangun sebelumnya (strategi SO, WO, ST, dan WT). Penentuan strategi prioritas ditentukan berdasarkan titik perpotongan dari skor total faktor internal (nilai kekuatan dikurangi nilai kelemahan) dengan skor total faktor eksternal (nilai peluang dikurangi ancaman).

\section{HASIL DAN PEMBAHASAN}

Analisis Faktor Internal dan Eksternal

Pembangunan hutan tanaman tidak hanya sekedar untuk merehabilitasi hutan yang tidak/kurang produktif. Pembangunan dan pengelolaan HTI yang baik secara simultan mempunyai manfaat ekonomi dan lingkungan, artinya perolehan manfaat ekonomi dari kayu yang dipanen untuk dipergunakan sebagai pasokan bahan baku industri sekaligus areal yang direhabilitasi akan memberi daya dukung ekologi dan lingkungan yang lebih baik. Skema REDD+ berpotensi untuk melindungi hutan dan mengurangi dampak perubahan iklim. Seandainya pembangunan dan pengelolaan HTI memenuhi standar sebagaimana disyaratkan dalam skema REDD+, maka HTI berpotensi untuk memperoleh manfaat finansial. Keberhasilan HTI untuk memenuhi skema REDD+ dapat dicapai jika terdapat sinergitas antara kekuatan internal dan peluang eksternal, serta sangat tergantung pada kelemahan internal dan ancaman eksternal yang ada. Berdasarkan hasil observasi terhadap data-data primer dan sekunder, serta pengamatan langsung di lapangan diperoleh faktor internal dan eksternal sebagai berikut : 
Tabel 1. Faktor Internal dan Eksternal dalam Penyusunan Strategi Pengelolaan HTI PT. Finnantara Intiga untuk REDD+

\begin{tabular}{|c|c|}
\hline \multicolumn{2}{|c|}{ Faktor Internal } \\
\hline Kekuatan (Strengths) & Kelemahan (Weaknesses) \\
\hline $\begin{array}{l}\text { - Mempunyai cadangan stok karbon total pada umur } 1-7 \\
\text { tahun sebesar } 690,73 \text { Ton/Ha (Ganjar et al., 2016) } \\
\text { - Mempunyai kemampuan untuk mensequestrasi } \mathrm{CO}_{2} \\
\text { 717.999,37 Ton/Tahun (Ganjar et al., 2016) } \\
\text { - Tersedia data dan sistem pengukuran pertumbuhan dan } \\
\text { stok tanaman yang baik, yang menjamin kepastian MRV } \\
\text { dalam REDD+ } \\
\text { - Komitmen perusahaan untuk mengelola hutan secara } \\
\text { lestari } \\
\text { - Kemampuan perusahaan untuk memenuhi sertifikasi } \\
\text { pengelolaan hutan lestari baik internasional maupun } \\
\text { nasional } \\
\text { - Pengalaman kerjasama dengan masyarakat }\end{array}$ & $\begin{array}{l}\text { - Kemampuan untuk menyelesaikan konflik } \\
\text { tata batas dan penggunaan areal oleh pihak } \\
\text { lain di luar sektor kehutanan yang masih } \\
\text { rendah } \\
\text { - Masih lemahnya perusahaan dalam } \\
\text { mengatasi gangguan keamanan hutan yang } \\
\text { berpotensi terjadinya illegal logging } \\
\text { - Masih rendahnya kemampuan merealisasikan } \\
\text { target penanaman }\end{array}$ \\
\hline \multicolumn{2}{|c|}{ Faktor Eksternal } \\
\hline Peluang (Opportunities) & Ancaman (Threats) \\
\hline $\begin{array}{l}\text { - Kebijakan internasional dalam mitigasi perubahan iklim } \\
\text { melalui REDD+ } \\
\text { - Dukungan pemerintah pusat dan daerah dalam bentuk } \\
\text { kebijakan dan kelembagaan dalam pelaksanaan REDD+ } \\
\text { - Keberadaaan institusi lain yang bisa membantu } \\
\text { pelaksanaan REDD+ (perguruan tinggi, LSM, dll) }\end{array}$ & $\begin{array}{l}\text { - Potensi perubahan kebijakan fungsi kawasan } \\
\text { oleh pemerintah pusat dan daerah } \\
\text { - Lemahnya kepastian dan penegakan hukum } \\
\text { di bidang kehutanan dan lingkungan } \\
\text { - Masuknya aktor lain yang mempunyai } \\
\text { kekuatan lebih besar, yang berpotensi } \\
\text { mengganggu kemantapan kawasan }\end{array}$ \\
\hline
\end{tabular}

Sumber : Pengolahan Data 2018

Selanjutnya disusun matriks untuk memetakan unsur-unsur faktor kekuatan dan kelemahan internal untuk menghadapi peluang dan ancaman, sehingga dihasilkan empat (4) alternatif strategi : strategi SO, strategi ST, Strategi WO, dan strategi WT, seperti pada Tabel 2 berikut ini : 
Tabel 2. Matriks Pengembangan Strategi Pengelolaan HTI PT. Finnantara Intiga untuk REDD+

\begin{tabular}{|c|c|c|}
\hline Faktor Eksternal & 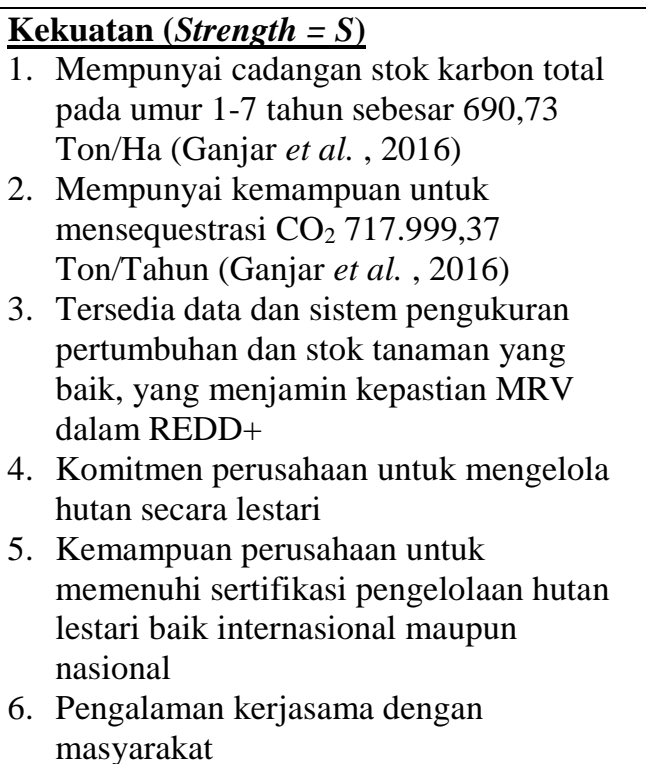 & $\begin{array}{l}\text { Kelemahan (Weakness }=\boldsymbol{W} \text { ) } \\
\text { 1. Kemampuan untuk menyelesaikan } \\
\text { konflik tata batas dan penggunaan } \\
\text { areal oleh pihak lain di luar sektor } \\
\text { kehutanan yang masih rendah } \\
\text { 2. Masih lemahnya perusahaan dalam } \\
\text { mengatasi gangguan keamanan } \\
\text { hutan yang berpotensi terjadinya } \\
\text { illegal logging } \\
\text { 3. Masih rendahnya kemampuan } \\
\text { merealisasikan target penanaman }\end{array}$ \\
\hline $\begin{array}{l}\text { Peluang }(\text { Opportunity }=\boldsymbol{O}) \\
\text { 1. Kebijakan internasional } \\
\text { dalam mitigasi perubahan } \\
\text { iklim melalui REDD+ } \\
\text { 2. Dukungan pemerintah } \\
\text { pusat dan daerah dalam } \\
\text { bentuk kebijakan dan } \\
\text { kelembagaan dalam } \\
\text { pelaksanaan REDD+ } \\
\text { 3. Keberadaaan institusi lain } \\
\text { yang bisa membantu } \\
\text { pelaksanaan REDD+ } \\
\text { (perguruan tinggi, LSM, } \\
\text { dll) }\end{array}$ & 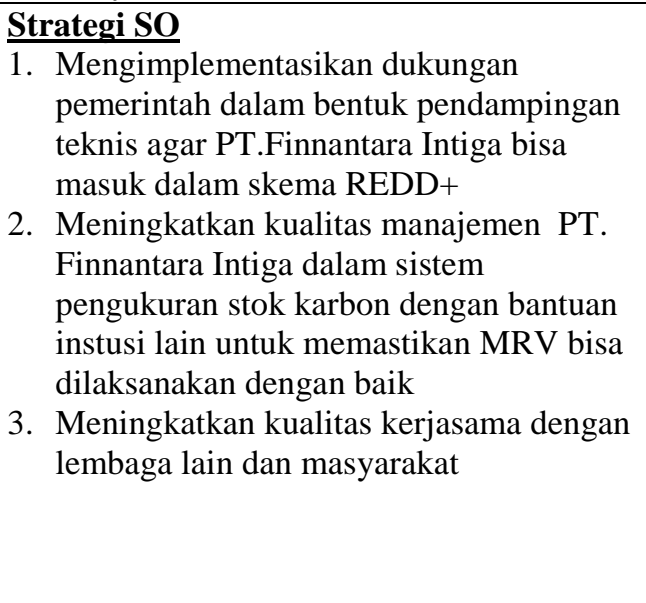 & $\begin{array}{l}\text { Strategi WO } \\
\text { 1. Mendukung terbentuknya Kesatuan } \\
\text { Pengelolaan Hutan (KPH) yang } \\
\text { menaungi areal PT. Finnantara } \\
\text { Intiga untuk menjamin kemantapan } \\
\text { dan keamanan kawasan hutan } \\
\text { 2. Meningkatkan kualitas manajemen } \\
\text { PT, Finnantara Intiga dengan } \\
\text { bantuan pihak lain untuk menjamin } \\
\text { tercapainya peningkatan stok } \\
\text { karbon dan pengelolaan hutan yang } \\
\text { lestari di HTI PT. Finnantara Intiga } \\
\text { melalui penelitian dan } \\
\text { pengembangan yang komprehensif } \\
\text { dan berkelanjutan, }\end{array}$ \\
\hline $\begin{array}{l}\text { Ancaman }(\text { Treats }=\text { T }) \\
\text { 1. Potensi perubahan } \\
\text { kebijakan fungsi kawasan } \\
\text { oleh pemerintah pusat dan } \\
\text { daerah akibat dinamika } \\
\text { pembangunan yang ada } \\
\text { 2. Lemahnya kepastian dan } \\
\text { penegakan hukum di } \\
\text { bidang kehutanan dan } \\
\text { lingkungan } \\
\text { 3. Masuknya aktor lain yang } \\
\text { mempunyai kekuatan } \\
\text { lebih besar, yang } \\
\text { berpotensi mengganggu } \\
\text { kemantapan kawasan }\end{array}$ & $\begin{array}{l}\text { Strategi ST } \\
\text { 1. Melakukan sinkronisasi perencanaan di } \\
\text { tingkat unit manajemen HTI } \\
\text { PT.Finnantara Intiga dengan perencanaan } \\
\text { di level yang lebih tinggi } \\
\text { 2. Meningkatkan kualitas manajemen } \\
\text { perusahaan untuk menjamin kemantapan } \\
\text { dan keamanan kawasan hutan } \\
\text { 3. Bekerjasama dengan masyarakat untuk } \\
\text { menjaga dan kemantapan dan keamanan } \\
\text { kawasan } \\
\text { 4. Mendorong terwujudnya good forestry } \\
\text { governence untuk kepastian berusaha dan } \\
\text { penegakan hukum di bidang kehutanan } \\
\text { dan lingkungan }\end{array}$ & $\begin{array}{l}\text { Strategi WT } \\
\text { 1. Mendukung terbentuknya Kesatuan } \\
\text { Pengelolaan Hutan (KPH) yang } \\
\text { menaungi areal PT.Finnantara } \\
\text { Intiga untuk menjamin kemantapan } \\
\text { dan keamanan kawasan hutan } \\
\text { sekaligus mendorong terwujudnya } \\
\text { good forestry governence untuk } \\
\text { kepastian berusaha dan penegakan } \\
\text { hukum di bidang kehutanan dan } \\
\text { lingkungan } \\
\text { 2. Membuat terobosan kerjasama } \\
\text { dengan perusahaan lain yang lebih } \\
\text { berpengalaman dan lebih kuat } \\
\text { sumberdayanya (modal, SDM, } \\
\text { peralatan, dll) }\end{array}$ \\
\hline
\end{tabular}

Sumber : Pengolahan Data 2018 
Adapun penjabaran dari Tabel 2 adalah sebagai berikut :

1. Strategi yang dilakukan dengan menggunakan kekuatan dan memanfaatkan peluang (Strategi SO) :

1. Mengimplementasikan dukungan pemerintah dalam bentuk pendampingan teknis agar PT. Finnantara Intiga bisa masuk dalam skema REDD+ (S1, S2, S4, S5, O1, $\mathrm{O} 2$ ), dengan penjabaran sebagai berikut :

- Dukungan pemerintah bisa dimulai dari tingkat pemerintah daerah, dimana Provinsi Kalimantan Barat berkomitmen untuk berkontribusi dalam mitigasi perubahan iklim. Sejalan dengan hal tersebut, maka kontribusi HTI PT. Finnantara Intiga dalam mengurangi emisi Kalimantan barat sebesar 3,89\% adalah merupakan subordinasi dari kontribusi Kalimantan Barat dalam mitigasi perubahan iklim secara nasional,

- Pembahasan dan diskusi yang lebih teknis perlu dilakukan untuk semakin terwujudnya implementasi skema REDD+ di HTI baik yang difasilitasi pemerintah pusat maupun daerah,

- Membentuk Forum atau Asosiasi Pengusaha Hutan yang berkomitmen dalam mitigasi perubahan iklim di daerah yang difasilitasi pemerintah pusat

2. Meningkatkan kualitas manajemen PT. Finnantara Intiga dalam sistem pengukuran stok karbon dengan bantuan instusi lain untuk memastikan MRV bisa dilaksanakan dengan baik (S3, O3), sebagai berikut :

- Melakukan kerjasama dalam pengukuran dan pengolahan data untuk MRV dengan pihak lain yang berkompeten

- Meningkatkan koordinasi dan komunikasi dengan para pihak terkait MRV sehingga data dan infromasi terkait implementasi REDD+ di HTI PT. Finnantara Intiga secara khusus dan Kalimantan Barat secara umum selalu update,

3. Meningkatkan kualitas kerjasama dengan lembaga lain dan masyarakat (S6, O3), sebagai berikut :

- Membuat terobosan kerjasama baru terkait akses terhadap insentif dana untuk implementasi REDD+

- Melibatkan masyarakat dalam pengelolaan HTI untuk menjalankan kewajiban pemberdayaan masyarakat (CSR) dan meredam potensi konflik,

2. Strategi memanfaatkan peluang untuk mengatasi kelemahan (Strategi WO), sebagai berikut :

1. Mendukung terbentuknya Kesatuan Pengelolaan Hutan (KPH) yang menaungi areal PT. Finnantara Intiga untuk menjamin kemantapan dan keamanan kawasan hutan $(\mathrm{O} 2$, W1, W2) :

- Membantu dalam menyediakan informasi dan data untuk pembentukan KPH di areal PT. Finnantara Intiga

- Melakukan kerjasama dengan $\mathrm{KPH}$ mengatasi permasalahan yang selama ini belum terselesaikan, seperti tata batas dan konflik lahan

2. Meningkatkan kualitas manajemen PT. Finnantara Intiga dengan bantuan pihak lain untuk menjamin tercapainya peningkatan stok karbon dan pengelolaan hutan yang 
lestari di HTI PT. Finnantara Intiga melalui penelitian dan pengembangan yang komprehensif dan berkelanjutan (O3, W3) :

- Melakukan kerjasama dengan pihak yang berkompeten (perguruan tinggi dan Lembaga Penelitian dan Pengembangan yang dimiliki instansi pusat atau daerah) untuk menjamin peningkatan stok karbon dan pengelolaan hutan yang lestari secara komprehensif dan berkelanjutan,

- Mengaplikasikan hasil penelitian kolaborasi di tingkat tapak

3. Strategi memanfaatkan kekuatan untuk meminimalkan ancaman (Strategi ST), dilakukan dengan cara sebagai berikut :

1. Melakukan sinkronisasi perencanaan di tingkat unit manajemen HTI PT. Finnantara Intiga dengan perencanaan di level yang lebih tinggi (S4, S5, T1)

- Menyusun rencana kerja HTI (RKT dan RKU) yang sinkron dengan Rencana Kehutanan di Tingkat Provinsi dan Pusat,

- Menyusun rencana kerja HTI yang sinkron dengan kebijakan lingkungan hidup di level Kabupaten, Provinsi, Nasional, dan internasional,

2. Meningkatkan kualitas manajemen perusahaan untuk menjamin kemantapan dan keamanan kawasan hutan (S4, S5, T2, T3)

- Melakukan pendidikan, latihan, dan penyegaran secara berkelanjutan terhadap organisasi kerja perusahaan yang bertanggung jawab pada kemantapan dan keamanan kawasan hutan
3. Bekerjasama dengan masyarakat untuk menjaga dan kemantapan dan keamanan kawasan (S5, T2, T3)

- Melibatkan masyarakat dalam penentuan tata batas HTI

- Melibatkan masyarakat dalam pekerjaan yang ada di HTI

- Melakukan program CSR

4. Mendorong terwujudnya good forestry governence untuk kepastian berusaha dan penegakan hukum di bidang kehutanan dan lingkungan (S4, S5, T2)

- Membuat Memorandum of Understanding (nota kesepahaman) dengan para pihak : pemerintah pusat, pemerintah daerah (kabupaten dan provinsi), lembaga masyarakat adat, kepolisian, kejaksaan, dan lainlain, untuk mendapatkan kepastian berusaha dan penegakan hukum,

4. Strategi untuk meminimalkan kelemahan dan ancaman yang ada (Strategi WT), dengan

cara sebagai berikut :

1. Mendukung terbentuknya Kesatuan Pengelolaan Hutan (KPH) yang menaungi areal PT. Finnantara Intiga untuk menjamin kemantapan dan keamanan kawasan hutan sekaligus mendorong terwujudnya good forestry governence untuk kepastian berusaha dan penegakan hukum di bidang kehutanan dan lingkungan (W1, W2, T1, T2)

- Proaktif mendukung terbentuknya KPH

2. Membuat terobosan kerjasama dengan perusahaan lain yang lebih berpengalaman dan lebih kuat sumberdayanya (modal, SDM, peralatan, dll) (W3, T3)

- Membangun komunikasi dengan pihak lain 
- Melakukan kerjasama teknis dengan pihak lain untuk mengatasi kelemahan dan ancaman yang ada

Analisis Grand Strategy

Analisis grand strategy dilakukan untuk menentukan strategi prioritas dari alternatif strategi yang telah dibangun sebelumnya (strategi SO, WO, ST, dan WT). Penentuan strategi prioritas ditentukan berdasarkan titik perpotongan dari skor total faktor internal (nilai kekuatan dikurangi nilai kelemahan) dengan skor total faktor eksternal (nilai peluang dikurangi ancaman).

Sebelumnya unsur-unsur faktor internal dan eksternal diberi nilai bobot dan peringkat berdasarkan penilaian responden. kemudian dihitung skornya. Skor merupakan hasil perkalian dari nilai bobot dengan peringkat, jika unsur kekuatan skornya lebih besar dari unsur kelemahan maka menunjukkan unsur kekuatan lebih dominan dibanding kelemahannya, begitu juga untuk peluang dan ancaman serta hal ini berlaku sebaliknya.

Tabel 3. Perhitungan Skor Faktor Internal dan Eksternal untuk Menentukan Grand Strategy

\begin{tabular}{|c|c|c|c|c|}
\hline \multirow{2}{*}{ No } & Unsur-unsur Strategi Faktor Internal & \multirow{2}{*}{ Bobot } & \multirow{2}{*}{ Peringkat } & \multirow{2}{*}{ Skor } \\
\hline & Kekuatan & & & \\
\hline 1 & $\begin{array}{l}\text { Mempunyai cadangan stok karbon total pada umur 1-7 tahun sebesar 690,73 } \\
\text { Ton/Ha (Ganjar } \text { et al. , 2016) }\end{array}$ & 0,063 & 3 & 0,189 \\
\hline 2 & $\begin{array}{l}\text { Mempunyai kemampuan untuk mensequestrasi } \mathrm{CO}_{2} 717.999,37 \text { Ton/Tahun } \\
\text { (Ganjar et al. , 2016) }\end{array}$ & 0,069 & 3,6 & 0,250 \\
\hline 3 & $\begin{array}{l}\text { Tersedia data dan sistem pengukuran pertumbuhan dan stok tanaman yang } \\
\text { baik, yang menjamin kepastian MRV dalam REDD+ }\end{array}$ & 0,069 & 4,8 & 0,333 \\
\hline 4 & Komitmen perusahaan untuk mengelola hutan secara lestari & 0,076 & 4,8 & 0,363 \\
\hline 5 & $\begin{array}{l}\text { Kemampuan perusahaan untuk memenuhi sertifikasi pengelolaan hutan } \\
\text { lestari baik internasional maupun nasional }\end{array}$ & 0,073 & 4,8 & 0,348 \\
\hline 6 & Pengalaman kerjasama dengan masyarakat & 0,076 & 4,4 & 0,333 \\
\hline \multicolumn{2}{|c|}{ Jumlah } & 0,426 & & $\mathbf{1 , 8 1 7}$ \\
\hline & Kelemahan & & & \\
\hline 1 & $\begin{array}{l}\text { Kemampuan untuk menyelesaikan konflik tata batas dan penggunaan areal } \\
\text { oleh pihak lain di luar sektor kehutanan yang masih rendah }\end{array}$ & 0,073 & 6,67 & 0,484 \\
\hline 2 & $\begin{array}{l}\text { Masih lemahnya perusahaan dalam mengatasi gangguan keamanan hutan } \\
\text { yang berpotensi terjadinya illegal logging }\end{array}$ & 0,057 & 7,33 & 0,416 \\
\hline 3 & Masih rendahnya kemampuan merealisasikan target penanaman & 0,054 & 5,33 & 0,286 \\
\hline \multicolumn{2}{|c|}{ Jumlah } & 0,183 & & $\overline{1,186}$ \\
\hline \multirow{2}{*}{ No } & Unsur-unsur Strategi Faktor Internal & \multirow{2}{*}{ Bobot } & \multirow{2}{*}{ Peringkat } & \multirow{2}{*}{ Skor } \\
\hline & Peluang & & & \\
\hline 1 & Kebijakan internasional dalam mitigasi perubahan iklim melalui REDD+ & 0,066 & 7 & 0,464 \\
\hline 2 & $\begin{array}{l}\text { Dukungan pemerintah pusat dan daerah dalam bentuk kebijakan dan } \\
\text { kelembagaan dalam pelaksanaan REDD+ }\end{array}$ & 0,073 & 8 & 0,580 \\
\hline 3 & $\begin{array}{l}\text { Keberadaaan institusi lain yang bisa membantu pelaksanaan REDD+ } \\
\text { (perguruan tinggi, LSM, dll) }\end{array}$ & 0,073 & 8 & 0,580 \\
\hline \multicolumn{2}{|c|}{ Jumlah } & 0,211 & & 1,625 \\
\hline & Ancaman & & & \\
\hline 1 & $\begin{array}{l}\text { Potensi perubahan kebijakan fungsi kawasan oleh pemerintah pusat dan } \\
\text { daerah }\end{array}$ & 0,050 & 6,667 & 0,336 \\
\hline 2 & $\begin{array}{l}\text { Lemahnya kepastian dan penegakan hukum di bidang kehutanan dan } \\
\text { lingkungan }\end{array}$ & 0,069 & 8,000 & 0,555 \\
\hline 3 & $\begin{array}{l}\text { Masuknya aktor lain yang mempunyai kekuatan lebih besar, yang berpotensi } \\
\text { mengganggu kemantapan kawasan }\end{array}$ & 0,060 & 6,000 & 0,360 \\
\hline \multicolumn{2}{|c|}{ Jumlah } & 0,180 & & 1,251 \\
\hline
\end{tabular}

Sumber : Pengolahan Data 2018 
Tabel 3 menunjukkan skor unsur kekuatan sebesar 1,817 dan kelemahan sebesar 1,186, maka selisih sebesar 0,631 (positif), begitu juga untuk unsur peluang lebih besar dari ancaman. Nilai selisih positif keduanya menunjukkan unsur-unsur kekuatan dan peluang yang dimiliki PT. Finnantara Intiga lebih dominan dari unsur kelemahan dan ancaman yang ada. Menurut Rangkuti
(2006) faktor internal dan eksternal dapat diproyeksikan dalam dua sumbu koordinat, dimana kekuatan dan kelemahan diproyeksikan dalam sumbu $\mathrm{x}$ (garis horisontal) dan peluang dan ancaman diproyeksikan dalam sumbu y (garis vertikal). Kekuatan dan peluang diberi tanda positif, sedangkan kelemahan dan ancaman diberi tanda negatif.

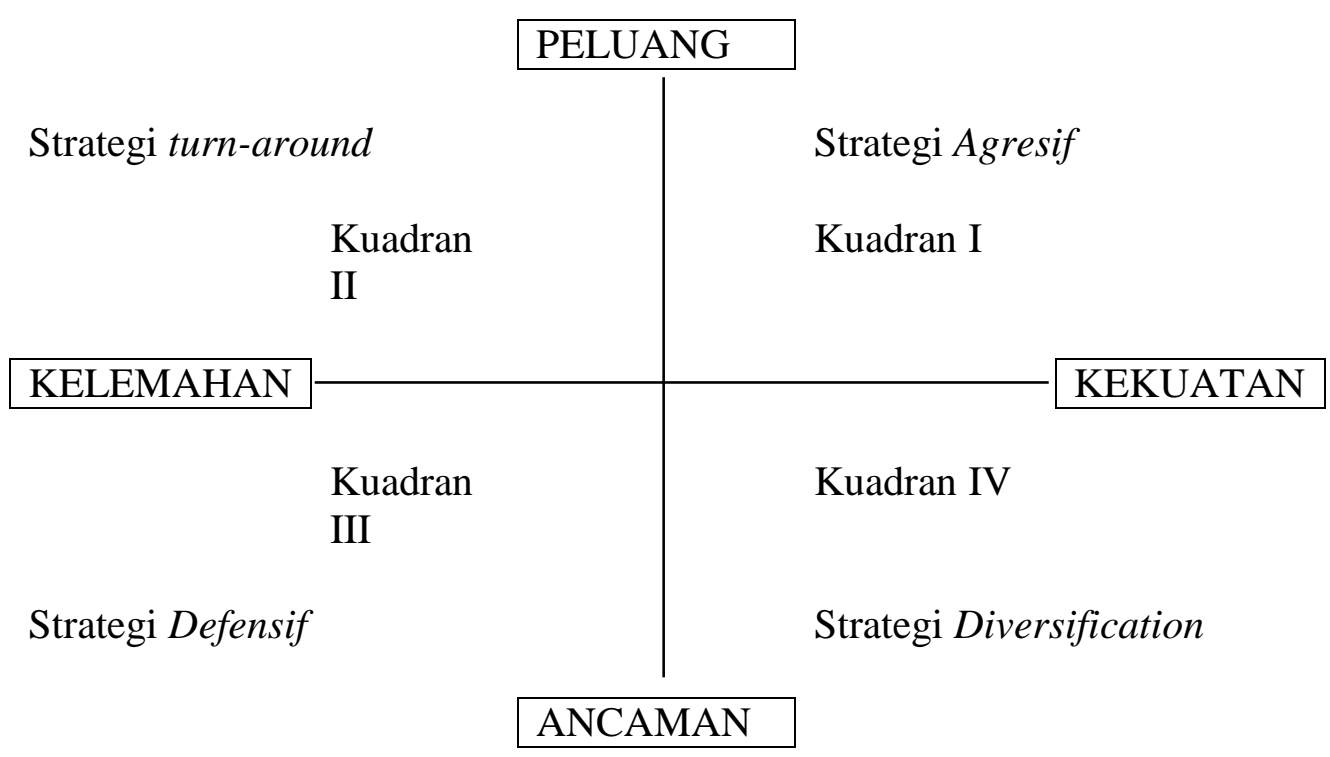

Gambar 1. Diagram SWOT (Rangkuti, 2006)

Berdasarkan skor pada Tabel 3, selisih faktor internal (kekuatan dikurangi kelemahan) dan selisih faktor eksternal (peluang dikurangi ancaman) adalah positif, maka perpotongan antara faktor internal dan eksternal terletak pada kuadran I. Pada kuadran I ini, prioritas strategi yang akan digunakan adalah strategi agresif (strategi SO), yaitu dengan menggunakan seluruh kekuatan dan memanfaatkan peluang yang ada. Bentuk strategi agresif tersebut adalah : (1) Mengimplementasikan dukungan pemerintah dalam bentuk pendampingan teknis agar PT. Finnantara Intiga bisa masuk dalam skema REDD+ (S1, S2, S4, S5, O1, O2). Dukungan pemerintah bisa dimulai dari tingkat pemerintah daerah, dimana Provinsi Kalimantan Barat berkomitmen untuk berkontribusi dalam mitigasi perubahan iklim. Sejalan dengan hal tersebut, maka kontribusi HTI PT. Finnantara Intiga dalam mengurangi emisi Kalimantan barat sebesar 3,89\% (Ganjar et al., 2016) adalah merupakan subordinasi dari kontribusi Kalimantan Barat dalam 
mitigasi perubahan iklim secara nasional. Perlu juga dilakukan pembahasan dan diskusi yang lebih teknis perlu dilakukan untuk semakin terwujudnya implementasi skema REDD+ di HTI baik yang difasilitasi pemerintah pusat maupun daerah. Membentuk Forum atau Asosiasi Pengusaha Hutan yang berkomitmen dalam mitigasi perubahan iklim di daerah yang difasilitasi pemerintah pusat juga perlu dilakukan untuk memperkuat jaringan kerjasama, (2) Meningkatkan kualitas manajemen PT. Finnantara Intiga dalam sistem pengukuran stok karbon dengan bantuan instusi lain untuk memastikan MRV bisa dilaksanakan dengan baik (S3, O3), dengan cara : melakukan kerjasama dalam pengukuran dan pengolahan data untuk MRV dengan pihak lain yang berkompeten, meningkatkan koordinasi dan komunikasi dengan para pihak terkait MRV sehingga data dan infromasi terkait implementasi REDD+ di HTI PT. Finnantara Intiga secara khusus dan Kalimantan Barat secara umum selalu update, (3) Meningkatkan kualitas kerjasama dengan lembaga lain dan masyarakat (S6, O3), yaitu dengan membuat terobosan kerjasama baru terkait akses terhadap insentif dana untuk implementasi REDD+, serta melibatkan masyarakat dalam pengelolaan HTI untuk menjalankan kewajiban pemberdayaan masyarakat (CSR) dan meredam potensi konflik.

Namun demikian, dalam implementasi strategi ke depan bersifat fleksibel, oleh karena itu usulan strategi yang berada pada kuadran II, III, dan IV dan kombinasinya dapat digunakan untuk melengkapi strategi prioritas. Suatu implementasi strategi seringkali juga berhadapan pada sesuatu kondisi relatif, misalnya suatu kekuatan (distinctive competence) hanya akan menjadi competitive advantage bagi suatu institusi apabila kekuatan tersebut terkait dengan lingkungan sekitarnya, apakah kekuatan itu dibutuhkan atau bisa mempengaruhi lingkungan di sekitarnya. Jika pada instutusi lain juga terdapat kekuatan yang dan institusi tersebut memiliki core competence yang sama, maka kekuatan harus diukur dari bagaimana kekuatan relatif suatu institusi dibandingkan dengan institusi yang lain. Sehingga dapat disimpulkan bahwa tidak semua kekuatan yang dimiliki institusi harus dipaksa untuk dikembangkan karena adakalanya kekuatan itu tidak terlalu penting jika dilihat dari lingkungan yang lebih luas. Hal-hal yang menjadi opposite dari kekuatan adalah kelemahan. Sehingga sama dengan kekuatan, tidak semua kelemahan dari institusi harus dipaksa untuk diperbaiki terutama untuk hal-hal yang tidak berpengaruh pada lingkungan sekitar. Dari sisi peluang, dapat dikatagorikan dalam tiga tingkatan : 1) Low, jika memiliki daya tarik dan manfaat yang kecil dan peluang pencapaiannya juga kecil, 2) Moderate, jika memiliki daya tarik dan manfaat yang besar namun peluang pencapaian kecil atau sebaliknya 3) Best, jika memiliki daya tarik dan manfaat yang tinggi serta peluang tercapaianya besar. Ancaman adalah segala sesuatu yang terjadi akibat trend perkembangan (persaingan) dan tidak bisa dihindari. Sementara itu, untuk ancaman juga bisa dilihat dari tingkat keparahan pengaruhnya (seriousness) dan 
kemungkinan terjadinya (probability of occurance). Sehingga dapat dikatagorikan : 1) Ancaman utama (major threats), adalah ancaman yang kemungkinan terjadinya tinggi dan dampaknya besar. Untuk ancaman utama ini, diperlukan beberapa contingency planning yang harus dilakukan institusi untuk mengantisipasi, 2) Ancaman tidak utama (minor threats), adalah ancaman yang dampaknya kecil dan kemungkinan terjadinya kecil, 3) Ancaman moderate, berupa kombinasi tingkat keparahan yang tinggi namun kemungkinan terjadinya rendah dan sebaliknya. Aspek lingkungan baik yang berasal dari lingkungan internal maupun eskternal yang mempengaruhi pola strategi institusi/lembaga dalam mencapai tujuan bersifat sangat dinamis. Kecepatan untuk membaca suatu kondisi yang berubah menjadi aspek keniscayaan yang harus diantisipasi agar pengelolaan HTI bisa berkontribusi dalam mitigasi perubahan iklim melalui skema REDD+.

\section{KESIMPULAN}

Prioritas strategi yang akan digunakan agar pengelolaan HTI oleh PT. Finnantara Intiga dapat masuk dalam skema REDD+ adalah strategi agresif (strategi $\mathrm{SO}$ ), yaitu dengan menggunakan seluruh kekuatan dan memanfaatkan peluang yang ada. Bentuk strategi agresif tersebut adalah : (1) Mengimplementasikan dukungan pemerintah dalam bentuk pendampingan teknis agar PT.Finnantara Intiga bisa masuk dalam skema REDD+. (2) Meningkatkan kualitas manajemen PT. Finnantara Intiga dalam sistem pengukuran stok karbon dengan bantuan institusi lain. (3) Meningkatkan kualitas kerjasama dengan lembaga lain dan masyarakat, yaitu dengan membuat terobosan kerjasama baru terkait akses terhadap insentif dana untuk implementasi REDD+, serta melibatkan masyarakat dalam pengelolaan HTI untuk menjalankan kewajiban pemberdayaan masyarakat (CSR) dan meredam potensi konflik. Aspek lingkungan baik yang berasal dari lingkungan internal maupun eksternal yang mempengaruhi pola strategi HTI dalam mencapai tujuan bersifat sangat dinamis, sehingga usulan strategi SO bersifat fleksibel oleh karena itu yang strategi pada kuadran II, III, dan IV dan kombinasinya dapat digunakan untuk melengkapi strategi prioritas.

\section{UCAPAN TERIMA KASIH (ACKNOWLEDGEMENT)}

Penelitian ini didukung oleh PT. Finnantara Intiga. Kami berterima kasih kepada rekan-rekan kami dari Universitas Tanjungpura dan Universitas Gadjah Mada yang memberikan wawasan dan keahlian yang sangat membantu dalam penelitian ini.

\section{DAFTAR PUSTAKA}

Angelsen A, Brockhaus M, Kanninen M, Sills E, Sunderlin WD, \& Wertz SK. (2010). Mewujudkan REDD+: Strategi nasional dan berbagai pilihan kebijakan. Bogor: Center for International Forest (CIFOR)

Anonim. (2016). Integrated Sustainable Forest Management Plan (ISFMP) Rencana Pengelolaan Hutan Terpadu Berkelanjutan IUPHHKHTI PT. Finnantara Intiga Kabupaten Sanggau-Sekadau dan Sintang Provinsi Kalimantan Barat. Pontianak: PT. Tera Widyagama (Konsultan Forestry-GIS-MappingSurvay) 
[Bappenas ] Badan Perencanaan dan Pembangunan Nasional. (2009). Indonesia Climate Change Sectoral Roadmap (ICCSR). Jakarta : Badan Perencanaan dan Pembangunan Nasional (Bappenas)

Ganjar Oki Widhanarto, Ris Hadi Purwanto, Ahmad Maryudi, \& Senawi. (2016). Assessing carbon pool of forest plantation to support REDD+ implementation in Indonesia. Proceeding on International Seminar on Science and Technology (ICST) Gadjah Mada University, Yogyakarta Oktober 2015. AIP Publishing : AIP Conference Proceedings 1755, $130008 \quad$ (2016); doi: 10.1063/1.4958552. View online: http://dx.doi.org/10.1063/1.4958552

Heriansyah, Ike. 2005. Potensi Hutan Tanaman Indsutri dalam Mensequester Karbon : Studi Kasus di Hutan Tanaman Akasia dan Pinus. Inovasi Online Vol.3/XVII/Maret 2005. PPI Jepang.

[MoEF] Ministry of Environmental and Forestry Republic of Indonesia. (2015). Intended Nationally Determined Contribution Republic of Indonesia. Submission to UNFCCC Secretariat. Directorate General of Climate Change. Jakarta : Ministry of Environment and Forestry Republic of Indonesia.

Rangkuti, F. 2006. Analisis SWOT Teknik Membedah Kasus Bisnis : Reorientasi Konsep Perencanaan Strategis untuk menghadapi Abad 21, Cetakan kedua belas, Penerbit PT Gramedia Pustaka Utama, Jakarta.
Sugiyono., 2004. Metode Penelitian Bisnis. Cetakan Ketujuh. Alfabeta. Bandung. 